Kontribusi Fisika Indonesia

Vol. 13 No.4, Oktober 2002

\title{
Struktur Vertikal Gelombang Planeter Di Mesosfer Ekuator Dari Pengamatan MF Radar Pontianak $\left(0.03^{\circ} \mathrm{LU}-109.3^{\circ} \mathrm{BT}\right)$
}

\author{
Dyah RM dan Buldan $M$ \\ Bidang Ionosfer dan Telekomunikasi LAPAN \\ Jl. Dr. Junjunan 133 Bandung \\ e-mail: dyah_rm@bdg.lapan.go.id
}

\begin{abstract}
Abstrak
Gelombang atmosfer memainkan peranan yang penting dalam dinamika atmosfer. Mekanisme pembentukan, penjalaran dan pecahnya gelombang atmosfer sangat menarik untuk dipelajari terutama di wilayah ekuator karena penelitian di lintang tengah mengindikasikan bahwa ekuator adalah dinamo atmosfer global.

Data angin dari pengamatan Medium Frequency Radar (MF Radar) di Pontianak pada ketinggian tertentu dari 78 km sampai dengan $98 \mathrm{~km}$, tahun 1996 digunakan untuk mendapatkan struktur vertikal variasi gelombang planeter angin zonal dan meridional di daerah mesosfer. Intensitas variasi angin zonal umumnya lebih tinggi dari pada angin meridional. Variasi gelombang planeter menurut posisi matahari juga akan didiskusikan. Berbeda dengan hasil penelitian di daerah lintang tinggi dan lintang tengah yang memiliki pola tertentu ${ }^{1)}$, di Pontianak variasi gelombang planeter menurut posisi matahari tidak menunjukkan pola tertentu.
\end{abstract}

Kata kunci : Dinamika atmosfer, gelombang planeter, angin zonal, angin meridional

\begin{abstract}
Atmospheric waves play a crucial role in atmospheric dynamics. Mechanism of generating, propagating, and breaking of waves are interesting to study, mainly in equator region, cause results of observation in the mid-latitude indicated equator region as global atmospheric dynamo.

Data from Medium Frequency (MF) Radar at Pontianak at the height of $78-98 \mathrm{~km}$ in 1996 used to obtain vertical structure of variation of planetary waves from zonal and meridional winds in the mesosphere. Generally, intensity of variation of zonal winds higher than meridional. Variation of waves related to sun would be discuss. Variation of planetary waves related to sun over Pontianak didn't show certain pattern. Results of observation at middle and higher latitude shown certain pattern of variation of planetary waves related to sun.
\end{abstract}

Keywords : Atmospheric dynamic, planetary waves, zonal winds, meridional winds.

\section{Pendahuluan}

Isu-isu perubahan lingkungan sangat erat berkaitan dengan dinamika atmosfer terutama transfer massa baik horisontal maupun vertikal. Gas rumah kaca karbondioksida $\left(\mathrm{CO}_{2}\right)$ dan gas perusak ozon seperti klorofluorokarbon (CIFC) dapat terdistribusi melalui aliran massa di atmosfer ${ }^{2)}$.

Studi-studi baik yang yang bersifat teori maupun eksperimen menunjukkan bahwa sistem dinamika atmosfer sangat kompleks dengan melibatkan gelombang dalam berbagai skala yang berdampak pada perubahan atmosfer global misalnya gelombang gravitasi internal, pasut, dan planeter. Mekanisme pembentukan, penjalaran, dan pecahnya gelombang tersebut berperan penting dalam dinamika atmosfer ${ }^{3)}$.

Hasil-hasil penelitian yang dilakukan di lintang tengah mengindikasikan bahwa daerah ekuator berperanan sebagai dinamo atmosfer global karena alasan-alasan berikut :

1. Daerah ekuator menerima emisi harian/albedo radiasi matahari paling tinggi dibandingkan dengan daerah lainnya

2. Sering terbentuk awan cumulonimbus
3. Gaya Coriolis sangat kecil di ekuator sehingga terjadi gaya apung (buoyancy).

Indonesia mempunyai keunikan yang agak berbeda dengan negara lainnya yang terletak pada wilayah ekuator, karena sebagian besar wilayah Indonesia berupa lautan ( $\pm 70 \%$ ), sehingga atmosfer Indonesia merupakan tempat yang potensial untuk dibangkitkannya gelombang atmosfer akibat energi raksasa yang dilepaskan melalui konveksi oleh laut ${ }^{4)}$.

Studi tentang variasi gelombang atmosfer dengan periode beberapa hari sampai beberapa minggu (gelombang planeter) dilakukan untuk mendapatkan struktur vertikal gelombang tersebut sehingga dapat memberi gambaran bagaimana interaksi yang terjadi dalam lapisan -lapisan atmosfer.

\section{Data dan Metode Pengolahan Data}

Sebagai pendukung penelitian ini digunakan data kecepatan angin rata-rata per jam zonal dan meridional dari stasiun MF radar Pontianak tahun 1996 dari bulan Januari s.d. bulan Desember.

Data MF Radar berupa kecepatan angin rata-rata dari ketinggian $78 \mathrm{~km}$ sampai dengan ketinggian $98 \mathrm{~km}$ dikelompokkan menjadi 11 lapisan ketinggian dengan 
interval $2 \mathrm{~km}$. Data tersebut kemudian dianalisis menggunakan analisis harmonik.

Data angin rata-rata per jam pada interval ketinggian tertentu diolah menggunakan analisis Fourier :

$$
V(t)=A_{0}+\sum_{n=1}^{n=3} A n \sin [2 x t / T n+\varphi n]
$$

dimana Tn adalah 24, 12, dan 8 jam.

Spektrum angin rata-rata zonal dan meridional dalam selang ketinggian antara $78 \mathrm{~km}$ dan $98 \mathrm{~km}$ diperoleh dengan memanfaatkan transformasi Fourier.

Spektrum angin rata-rata zonal dan meridional yang didapatkan kemudian digunakan untuk mendapatkan struktur vertikal dari gelombang planeter di atas Pontianak.

\section{Hasil dan Pembahasan}

Spektrum angin rata-rata zonal dan meridional yang sudah didapatkan kemudian digambarkan sebagai kontur sehingga akan terlihat periode-periode gelombang yang muncul untuk setiap ketinggian dalam rentang waktu satu tahun. Gambar 1. memperlihatkan salah satu contoh spektrum angin zonal rata-rata yang diperoleh dari analisis harmonik dan transformasi Fourier sebelum ditampilkan dalam bentuk kontur. Gambar 2 . memperlihatkan salah satu contoh kontur spektrum kecepatan angin rata-rata. Secara keseluruhan hasil yang diperoleh dapat dilihat dalam tabel 1. dan tabel 2.

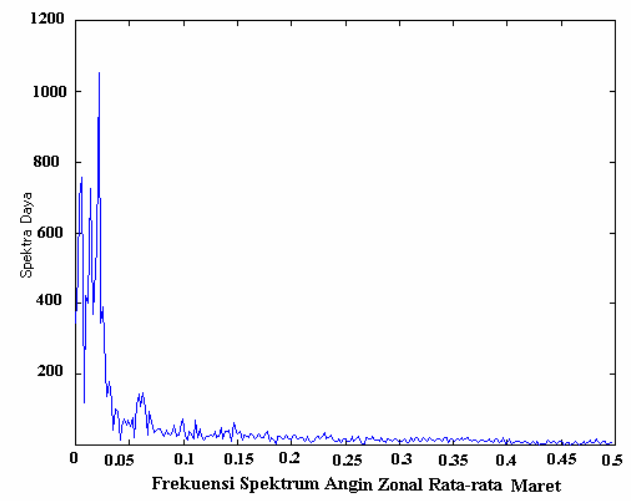

Gambar 1. Spektrum angin zonal rata-rata bulan Maret pada ketinggian $80 \mathrm{~km}$.

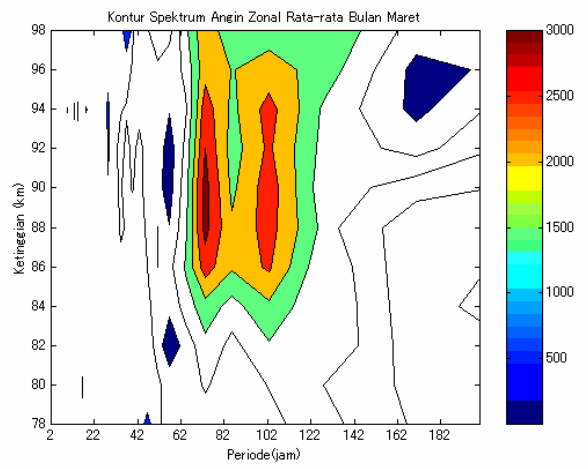

Gambar 2. Kontur spektrum kecepatan angin rata-rata zonal bulan Maret.
Tabel 1. Periode dominan gelombang dari spektrum angin rata-rata meridional.

\begin{tabular}{|l|c|c|}
\hline \multicolumn{1}{|c|}{ Bulan } & T (jam) & h (km) \\
\hline Januari & 52 & 96 \\
& 250 & 96 \\
\hline Februari & 55 & $90-94$ \\
\hline Maret & 50 & $87-97$ \\
\hline April & 52 & $84-96$ \\
\hline Mei & $122-160$ & 86 \\
\hline Juni & 127 & 94 \\
\hline Juli & 47 & $90-94$ \\
\hline Agustus & 177 & $90-92$ \\
\hline September & 52 & $86-92$ \\
\hline Oktober & 47 & $89-94$ \\
\hline November & 100 & $86-90$ \\
\hline Desember & $177-200$ & $84-90$ \\
\hline
\end{tabular}

Tabel 2. Periode dominan gelombang dari spektrum angin rata-rata zonal.

\begin{tabular}{|l|c|c|}
\hline \multicolumn{1}{|c|}{ Bulan } & T (jam) & h (km) \\
\hline Januari & 132 & $86-88$ \\
\hline Februari & $52-62$ & $86-90$ \\
& 57 & 96 \\
\hline Maret & 77 & $88-92$ \\
\hline April & 127 & $86-89$ \\
\hline Mei & 28 & $84-98$ \\
& $102-152$ & $88-92$ \\
\hline Juni & 72 & 94 \\
& 102 & 94 \\
& $144-182$ & 94 \\
& $152-242$ & 98 \\
\hline Juli & 172 & $86-88$ \\
\hline Agustus & $102-132$ & $88-94$ \\
\hline September & 25 & $85-90$ \\
& 27 & $84-90$ \\
& $127-217$ & $84-92$ \\
\hline Oktober & 127 & $86-94$ \\
\hline November & 92 & $84-98$ \\
& 122 & $88-90$ \\
\hline Desember & 47 & $94-96$ \\
\hline
\end{tabular}

Dari tabel 1 dan tabel 2 terlihat bahwa secara umum variasi spektrum angin rata-rata zonal lebih tinggi daripada spektrum angin rata-rata meridional.

Periode dominan gelombang dari spektrum angin rata-rata meridional yang muncul berkisar antara 47 jam sampai dengan 250 jam, pada ketinggian antara $84 \mathrm{~km}$ sampai dengan ketinggian $96 \mathrm{~km}$.

Periode dominan gelombang dari spektrum angin rata-rata zonal yang muncul berkisar antara 47 jam sampai dengan 152 jam, pada ketinggian antara $84 \mathrm{~km}$ sampai dengan ketinggian $98 \mathrm{~km}$.

Berdasarkan penelitian yang sudah dilakukan sebelumnya diperoleh indikasi munculnya gelombang di 
stratosfer atas dan mesosfer atas dengan periode dua harian sampai dengan periode lima hari yang merupakan periode gelombang planeter (Rodgers, 1976). Sementara untuk data di lintang rendah musim panas juga ditemui gelombang-gelombang dengan periode yang sama yaitu sekitar dua harian dan amplitudo gelombang maksimum berada di mesosfer (Rodgers, 1981). Bila dikaitkan dengan hasil yang telah diperoleh dalam studi ini maka untuk data angin rata-rata meridional di atas Pontianak pada tahun 1996 terlihat periode-periode yang muncul adalah periode 2-3 hari pada bulan-bulan Januari, Februari, Maret, April, Juli, September, dan Oktober, serta periode 5 hari pada bulan Juni.

Untuk data angin rata-rata zonal di atas Pontianak pada tahun 1996 terlihat periode-periode yang muncul adalah periode 2-3 hari pada bulan-bulan Desember, Februari, dan Juni serta periode 5 hari pada bulan Januari, April, Mei, Agustus, September, Oktober, dan November. Sedangkan pada bulan Juli tidak ditemui munculnya gelombang skala planeter.

Dari hasil pengolahan data juga terlihat bahwa gelombang planeter yang terjadi cukup banyak terutama pada data angin rata-rata meridional adalah gelombang planeter dengan periode sekitar dua harian (quasi two-day wave).

Apabila kita bandingkan gelombang periode dua harian (quasi two-day wave) di atas Pontianak dengan penelitian-penelitian di tempat lain, di atas Pontianak gelombang periode dua harian tidak mempunyai pola waktu kejadian yang tertentu. Hal ini berbeda dengan hasil pengamatan di lintang tinggi dan lintang tengah. Di lintang tengah gelombang planeter dua hari-an terjadi pada musim panas (Juni, Juli, Agustus). Di Australia gelombang ini terjadi pada bulan-bulan November, Desember, dan Januari.

Pengamatan gelombang planeter di atas Pontianak dikaitkan dengan posisi matahari, pada saat matahari sejajar ekuator gelombang planeter muncul dalam arah zonal (barat-timur) pada bulan Maret dan arah meridional (utara-selatan) pada bulan Maret dan September.

Dari kontur spentrum angin rata-rata zonal terlihat ada beberapa bulan dimana gelombang dengan spektrum yang kuat lebih dari satu. Misalnya bulan Juni pada ketinggian sekitar 94 sampai dengan $98 \mathrm{~km}$, muncul periode 3 hari, periode sekitar 4 hari, periode sekitar 6 hari, dan dan periode 10 hari. Hal sama juga terjadi pada bulan Februari, Mei, September, dan November.

Gelombang planeter yang muncul semuanya berada pada ketinggian di atas lapisan mesopause, hal ini mendukung hasil penelitian sebelumnya bahwa kemungkinan gelombang yang terbangkitkan di lapisan troposfer akan pecah di lapisan ini (Holton, 1987).

\section{Kesimpulan}

1. Di lapisan atmosfer menengah ekuator (mesosfer) yang dalam hal ini diwakili oleh Pontianak, muncul gelombang-gelombang planeter baik dalam arah zonal maupun meridional dengan periode-periode antara 2-3 hari dan 5 hari.

2. Variasi gelombang dalam arah zonal lebih tinggi dibandingkan dengan variasi dalam arah meridional.

3. Dari struktur vertikal gelombang diketahui bahwa gelombang planeter terjadi pada ketinggian di atas lapisan mesopause.

4. Hasil yang diperoleh dapat dimanfaatkan untuk melihat profil gelombang pada ketinggian tertentu.

\section{Daftar Pustaka}

1. Rodgers, C.D., Prata, A.J., Evidence for a Travelling Two Day Wave in The Middle Atmosphere, Journal of Geophysical Research, Vol. 86, No. C10, hal 96619664,1981.

2. Maekawa, R., Observations of Gravity Waves in the Mesopause Region by Multicolor Airglow Imaging, Dept. of Communications and Computer Engineering Graduate School of Informatics, Kyoto University, 2000.

3. Shimizu, A., Tsuda, T., Characteristics of Kelvin waves and gravity waves observed with radiosondes over Indonesia, J. Geophys. Res., 102, 26,15926,171, 1997.

4. Kato, S., Tri Wahyu Hadi, Joko Wiratmo, Dinamika Atmosfer, Penerbit ITB, 1998. 